\section{AGPAT2 is mutated in congenital generalized lipodystrophy linked to chromosome 9q34}

\author{
Published online: 22 April 2002, DOI: 10.1038/ng880
}

Congenital generalized lipodystrophy is an autosomal recessive disorder characterized by marked paucity of adipose tissue, extreme insulin resistance, hypertriglyceridemia, hepatic steatosis and early onset of diabetes. We report several different mutations of the gene (AGPAT2) encoding 1-acylglycerol-3-phosphate O-acyltransferase 2 in 20 affected individuals from 11 pedigrees of diverse ethnicities showing linkage to chromosome 9q34. The AGPAT2 enzyme catalyzes the acylation of lysophosphatidic acid to form phosphatidic acid, a key intermediate in the biosynthesis of triacylglycerol and glycerophospholipids. AGPAT2 mRNA is highly expressed in adipose tissue. We conclude that mutations in AGPAT2 may cause congenital generalized lipodystrophy by inhibiting triacylglycerol synthesis and storage in adipocytes. genital generalized lipodystrophy (also known as Berardinelli-Seip syndrome) to the CGL1 locus on chromosome 9q34 using genetic linkage analysis of 17 families $^{1}$. We identified additional families with CGLaffected individuals (CG3700, 5700 and 7000; Fig. 1a), who showed no mutations in BSCL2 (ref. 2), located on chromosome 11q13. Linkage to CGL1 was confirmed in these pedigrees using $9 q 34$ microsatellite markers as previously described ${ }^{1}$. Recombination mapping in pedigrees CG7000 and CG600 reduced the critical region to approximately $0.86 \mathrm{Mb}$ between $r s 1747838$ and DPP7 (see Fig. 1b, and Web Fig. A and Web Table A online). Sequencing of the exons and splice-site junctions of AGPAT2 located in this interval ${ }^{3,4}$ revealed homozygous or compound heterozygous mutations in CGL-affected individuals of 11 pedigrees showing linkage to 9q34 (see Table 1 and Web Fig. A online).

Fig. 1 CGL-affected pedigrees, haplotype mutations and expression analysis of AGPAT. a, Pedigrees of families with CGL. Individuals for whom DNA was available are indicated by an arrowhead. For simplicity, only those individuals who contribute to understanding of the consanguinity loops are shown for pedigree CG7000. $\boldsymbol{b}$, Haplotypes of affected individuals from the CG7000 pedigree, linked to the $9 q 34$ region. Gray areas indicate regions of homozygosity. Microsatellite loci are shown on the left. The individuals are numbered as shown in $a$. The paternal haplotype is shown in the right bar and the maternal haplotype in the left bar. c, Mutations in individuals of pedigree CG7000. Deletion of exons 3 and 4 is seen in affected individuals from CG7000, whereas parents of affected subjects show no deletions. $\boldsymbol{d}$, Expression of AGPAT mRNAs in human tissues. Gel images obtained from RT-PCR show that in adipose tissue, AGPAT2 was expressed twofold more than AGPAT1. In liver, expression of both AGPAT1 and AGPAT2 was the same; in skeletal muscle, AGPAT1 was expressed 1.8-fold more than AGPAT2. Expression of AGPAT3, AGPAT4 and AGPAT5 was barely detectable. The results were normalized to the signal generated from G3PDH. Details of the methods are provided as Web Note A.
We have previously mapped a form of con-
Affected individuals from pedigree CG7000 were homozygous with respect to a deletion of exons 3 and 4 (Fig. 1c) resulting in a frameshift mutation and premature termination codon. This mutation was confirmed in lymphoblastderived cDNA of individual CG7000.8. Affected individuals homozygous for an identical nonsense mutation (Arg63X) were identified in families from Turkey (CG5700) and Belgium (CG3700). A homozygous splice-site mutation resulting in a deletion of two amino acids starting at codon 221 was found in the affected individual from pedigree CG3500. Affected individuals from two African American families (CG400 and CG900) were homozygous with respect to a splice-site mutation (IVS4-2A $\rightarrow \mathrm{G}$ ) resulting in a frameshift and a premature termination codon (Gln196fsX228). This same splice-site mutation was identified in the heterozygous state in individuals from pedigrees CG3200, CG600 (African Caribbean families) and CG800 (African American family). Affected compound heterozygotes from these families were found to have a missense mutation, a frameshift mutation and a single-amino acid deletion, respectively. The affected $a$

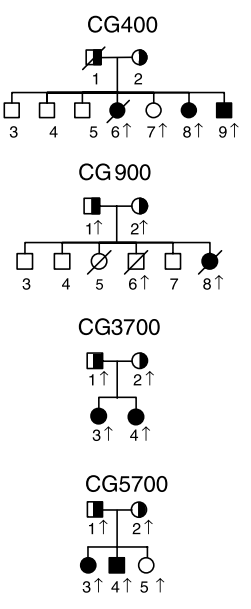

$b$

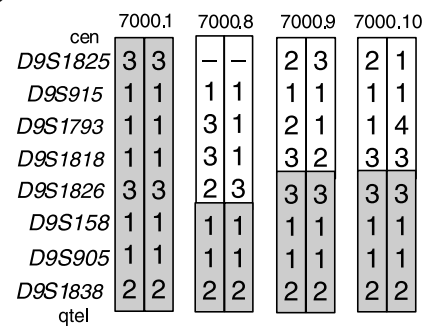

CG800

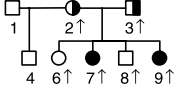

CG3500

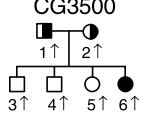

CG7000

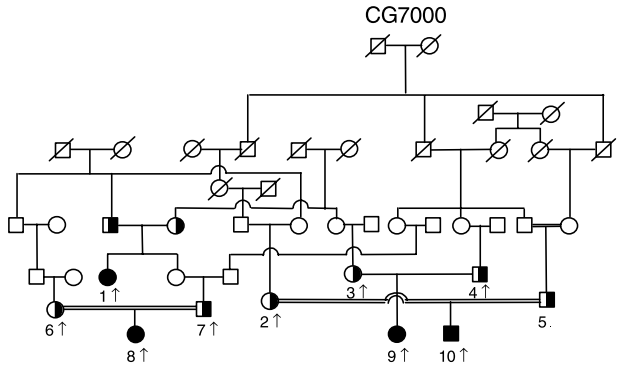

$c$

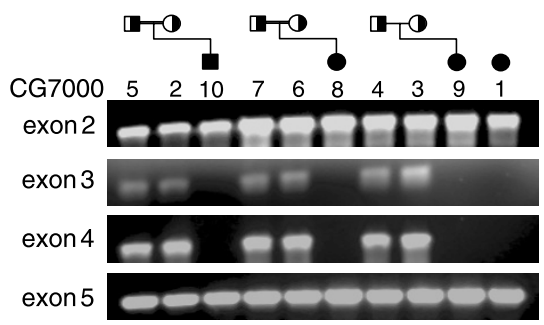

$d$

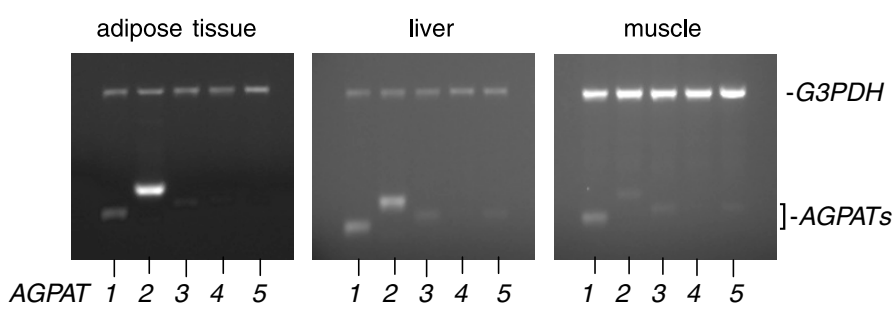




\begin{tabular}{|c|c|c|c|c|c|c|c|c|c|c|c|}
\hline Pedigree & $\begin{array}{l}\text { Ethnicity, } \\
\text { origin }\end{array}$ & $\begin{array}{l}\text { Nucleotide } \\
\text { alteration(s) }\end{array}$ & $\begin{array}{l}\text { Amino-acid } \\
\text { change(s) }\end{array}$ & Status & $\begin{array}{c}\text { Individual } \\
\text { no. }\end{array}$ & $\begin{array}{l}\text { Age/ } \\
\text { Sex }\end{array}$ & $\begin{array}{l}\text { Body fat } \\
(\%)\end{array}$ & $\begin{array}{l}\text { Serum } \\
\text { leptin } \\
(\mathrm{ng} / \mathrm{mL})\end{array}$ & $\begin{array}{c}\text { DM/ } \\
\text { age of } \\
\text { onset }(y)\end{array}$ & $\begin{array}{l}\text { Insulin } \\
\text { dose } \\
\text { (units/d) }\end{array}$ & Ref. \\
\hline CG7000 & European, Portugal & $\begin{array}{l}317-588 \text { del } \\
\text { (ex 3-4 del) }\end{array}$ & Gly106fsX188 & Hom & $\begin{array}{r}1 \\
8 \\
9 \\
10\end{array}$ & $\begin{array}{l}43 / \mathrm{F} \\
1 / \mathrm{F} \\
10 / \mathrm{F} \\
1 / \mathrm{M}\end{array}$ & $\begin{array}{l}\text { NA } \\
\text { NA } \\
\text { NA } \\
\text { NA }\end{array}$ & $\begin{array}{l}\text { NA } \\
\text { NA } \\
\text { NA } \\
\text { NA }\end{array}$ & $\begin{array}{l}- \\
- \\
- \\
-\end{array}$ & & \\
\hline CG5700 & European, Turkey & $202 C \rightarrow T$ & Arg68X & Hom & $\begin{array}{l}3 \\
4\end{array}$ & $\begin{array}{l}53 / \mathrm{F} \\
50 / \mathrm{M}\end{array}$ & $\begin{array}{r}11.6^{*} \\
7.2^{*}\end{array}$ & $\begin{array}{l}1.3 \\
0.7\end{array}$ & $\begin{array}{l}+/ 32 \\
+/ 40\end{array}$ & $\begin{array}{r}100 \\
-\end{array}$ & \\
\hline CG3700 & European, Belgium & $202 C \rightarrow T$ & Arg68X & Hom & $\begin{array}{l}3 \\
4\end{array}$ & $\begin{array}{l}17 / F \\
15 / F\end{array}$ & $\begin{array}{l}17.0^{*} \\
15.0^{*}\end{array}$ & $\begin{array}{l}1.1 \\
0.8\end{array}$ & $\begin{array}{l}+/ 11 \\
+/ 9\end{array}$ & $\begin{array}{l}1,200 \\
3,000\end{array}$ & 15 \\
\hline CG3500 & Hispanic, US & IVS5-2A $\rightarrow C$ & 221delGlyThr & Hom & 6 & $31 / \mathrm{F}$ & NA & 0.6 & $+/ 27$ & & \\
\hline CG400 & African American, US & IVS4-2A $\rightarrow G$ & Gln196fsX228 & Hom & $\begin{array}{l}6 \\
8 \\
9\end{array}$ & $\begin{array}{l}23 / \mathrm{F} \\
37 / \mathrm{F} \\
33 / \mathrm{M}\end{array}$ & $\begin{array}{l}\text { NA } \\
4.1 \text { * } \\
\text { NA }\end{array}$ & $\begin{array}{l}\text { NA } \\
0.6 \\
\text { NA }\end{array}$ & $\begin{array}{c}+/ \text { NA } \\
+/ 17 \\
-\end{array}$ & $\begin{array}{l}- \\
- \\
-\end{array}$ & 13,15 \\
\hline CG900 & African American, US & IVS4-2A $\rightarrow$ G & Gln196fsX228 & Hom & 8 & 23/F & 3.3 & 1.1 & $+/ 16$ & 220 & 14 \\
\hline CG600 & African Caribbean, UK & $\begin{array}{l}\text { IVS4-2A } \rightarrow \text { G } \\
683 T \rightarrow C\end{array}$ & $\begin{array}{l}\text { Gln196fsX228 } \\
\text { Leu228Pro }\end{array}$ & Het & $\begin{array}{l}5 \\
6\end{array}$ & $\begin{array}{l}15 / \mathrm{F} \\
13 / \mathrm{M}\end{array}$ & $\begin{array}{l}7.8 \\
1.9\end{array}$ & $\begin{array}{l}0.7 \\
0.7\end{array}$ & $\begin{array}{c}+/ 12 \\
-\end{array}$ & $\begin{array}{r}980 \\
-\end{array}$ & \\
\hline CG800 & African American, US & $\begin{array}{l}\text { IVS4-2A } \rightarrow \text { G } \\
\text { 377insT }\end{array}$ & $\begin{array}{l}\text { Gln196fsX228 } \\
\text { Leu126fsX146 }\end{array}$ & Het & $\begin{array}{l}7 \\
9\end{array}$ & $\begin{array}{l}31 / F \\
29 / F\end{array}$ & $\begin{array}{l}5.6^{*} \\
0\end{array}$ & $\begin{array}{l}0.7 \\
2.2\end{array}$ & $\begin{array}{l}+/ 13 \\
+/ 12\end{array}$ & $\begin{array}{l}750 \\
300\end{array}$ & 14,15 \\
\hline CG700 & European descent, US & $\begin{array}{l}\text { 406G } \rightarrow \text { A } \\
\text { 504delGA }\end{array}$ & $\begin{array}{l}\text { Gly136Arg } \\
\text { Val167fsX183 }\end{array}$ & Het & 4 & $42 / \mathrm{F}$ & 7.9 & 0.9 & $+/ 30$ & - & \\
\hline CG3300 & European descent, US & $\begin{array}{l}716 \mathrm{C} \rightarrow \mathrm{T} \\
916 \mathrm{C} \rightarrow \mathrm{G} 3^{\prime} \text { UTR }\end{array}$ & Ala239Val & Het & 3 & $29 / F$ & NA & $<0.5$ & $+/ 10$ & 80 & \\
\hline
\end{tabular}

*Measured using dual-energy X-ray absorptiometry; other estimates were made with hydrodensitometry. A plus sign indicates present; a minus sign, absent. Serum leptin was measured by a commercial radioimmunoassay. Patient numbers are the same as those shown in Fig. 1a. Het, compound heterozygote; Hom, homozygous; NA, not available; UTR, untranslated region.

individual in pedigree CG700 was a compound heterozygote having one missense and one frameshift mutation. The affected individual from pedigree CG3300 was found to be heterozygous for a missense mutation. We did not detect a coding or splice-site mutation on the other allele; however, we did find a mutation in the 3' UTR, which we suggest has a deleterious effect on gene expression.

Mutations segregated in all pedigrees in accordance with autosomal recessive inheritance. Sequencing of exons 2-5, which contained all of the mutations seen in individuals with CGL, of 50 unaffected subjects (25 each of European and African origin) revealed no mutations. All of the chromosomes carrying the IVS4- $2 \mathrm{~A} \rightarrow \mathrm{G}$ mutation in five families of African origin had the same haplotype for seven markers extending $33 \mathrm{~kb}$, suggesting a common ancestral mutation (see Web Table B online).

The AGPAT2 protein has 278 amino acids and belongs to the family of acyltransferases ${ }^{5}$ and catalyzes an essential reaction in the biosynthetic pathway of glycerophospholipids and triacylglycerol in eukaryotes. To our knowledge, CGL is the first documented human disease caused by a mutation in this pathway. The first step of the pathway involves glycerol3-phosphate acyltransferase (GPAT), which acylates glycerol-3-phosphate at the first carbon (sn-1 position) to form lysophosphatidic acid. AGPAT2 catalyzes acylation of lysophosphatidic acid at the second carbon (sn-2 position) to form phosphatidic acid. Dephosphorylation of phosphatidic acid occurs next, to form 1,2 diacylglycerol, which is acylated to form triacylglycerol using diacylglycerol acyltransferase (DGAT).

The AGPAT2 protein shows $48 \%$ identity with AGPAT1, and much less homology to three other related proteins AGPAT3, AGPAT4 and AGPAT5 (refs 5,7). All known AGPATs share two motifs: $\mathrm{NHX}_{4} \mathrm{D}$, which is involved in catalytic function, and EGTR, which is involved in substrate binding and recognition. The mutations Arg68X, Gly106fsX188 and Leu126fsX146 affect either one or both motifs. The two splice-site mutations retain these motifs; however, IVS4-2A $\rightarrow \mathrm{G}$ results in an aberrant and truncated protein and IVS5-2A $\rightarrow \mathrm{C}$ causes the deletion of two amino acids and may disrupt secondary structure of the protein, as can the mutation 140delPhe. The three missense mutations, Leu228Pro, Ala239Val and Gly136Arg, result in nonconservative amino-acid changes at evolutionary conserved sites between the human and mouse proteins.

The AGPAT1 mRNA is ubiquitously expressed in human tissues, with the greatest amount of expression in skeletal muscle ${ }^{6}$. Expression of AGPAT2 is more tissue-restricted, occuring at high levels in liver and heart tissues but almost undetectable in brain ${ }^{3,4}$. Amplification of all AGPAT mRNA in normal human omental adipose tissue revealed at least twofold higher expression of AGPAT2 than AGPAT1 (Fig. 1d). AGPAT2 was expressed at lower level in liver and much less in skeletal muscle. Homologues of AGPAT2, AGPAT3, AGPAT4 and AGPAT5 were barely detectable (Fig. $1 d$ ).

The AGPAT2 enzyme is likely to affect triacylglycerol synthesis in adipose tissue and may cause lipodystrophy by resulting in triglyceride-depleted adipocytes. It is also likely that reduced AGPAT2 activity could increase tissue levels of lysophosphatidic acid, which may affect adipocyte functions ${ }^{8}$. Lysophosphatidic acid is a ligand for G-protein coupled receptors and may have a role in preadipocyte proliferation and adipogenesis ${ }^{8,9}$. Decreased AGPAT2 activity could also lead to reduced bioavailability of phosphatidic acid and phosphoglycerols (phosphatidylinositol, phosphatidylcholine and phosphatidylethanolamine), which are important in intracellular signaling and could affect adipocyte functions ${ }^{10}$.

The gene BSCL2 encodes a protein of unknown function ${ }^{2}$. Individuals with CGL who carry BSCL2 mutations seem to have mild mental retardation and cardiomyopathy ${ }^{11,12}$, which are not seen in the individuals we studied who have AGPAT2 mutations. Based on the high expression of 
BSCL2 in brain and weak expression in adipocytes, a primary defect in hypothalamic pituitary axis has been suggested ${ }^{2}$. Our data suggest that mutations in AGPAT2 may cause congenital generalized lipodystrophy by inhibiting triacylglycerol synthesis in adipocytes. Thus, different forms of congenital generalized lipodystrophy may be caused by disruption of distinct pathways.

GenBank accession numbers. AGPAT1 $\mathrm{cDNA}$ XM_057885; AGPAT2 cDNA, AF000237; AGPAT3 cDNA, XM_036003; AGPAT4 cDNA, XM 004374; AGPAT5 cDNA, XM_034829; mouse Agpat2 cDNA, AY072769.

Note: Supplementary information is available on the Nature Genetics website.

\section{Acknowledgments}

We thank the members of the families studied for their invaluable contribution to this project; $A$. Osborn, T. Petricek and A. Nguyen for management of DNA and patient databases, illustrations and technical assistance; R. Wilson and B. Crider for help in genotyping; J. Cohen for providing DNA samples of control subjects; C. Helms and J. Dawes for technical assistance and the nursing and dietetic services of the General Clinical Research Center for patient care support. This work was supported by grants from the National Institutes of Health and by the Southwestern Medical Foundation.

\section{Competing interests statement}

The authors declare that they have no competing financial interests.

Anil K. Agarwal ${ }^{1}$, Elif Arioglư ${ }^{2}$, Salome de Almeida ${ }^{3}$, Nurullah Akkoc ${ }^{4}$, Simeon I. Taylor ${ }^{2}$, Anne M. Bowcock ${ }^{5}$, Robert I. Barnes $^{6}$ \& Abhimanyu Garg ${ }^{1}$

${ }^{1}$ Department of Internal Medicine, Division of Nutrition and Metabolic Diseases and Center for Human Nutrition, McDermott Center for Human Growth and Development, University of Texas Southwestern Medical Center, 5323 Harry Hines Blvd, Dallas, Texas 75390, USA. ${ }^{2}$ Diabetes Branch, National Institute of Diabetes and Digestive and Kidney Diseases, Bethesda, Maryland, USA.

${ }^{3}$ Servico de Genetica Medica, Hospital de Dona Estefania, Lisboa, Portugal. ${ }^{4}$ Dokuz Eylul University School of Medicine, Department of Internal Medicine, Inciralti, Izmir, Turkey. ${ }^{5}$ Division of Human Genetics, Departments of
Genetics, Pediatrics and Medicine, Washington University School of Medicine, St Louis, Missouri, USA. ${ }^{6} \mathrm{McD}$ ermott Center for Human Growth and Development, University of Texas Southwestern Medical Center, Dallas, Texas, USA.

Correspondence should be addressed to A.G. (email: abhimanyu.garg@utsouthwestern.edu).

Received 3 January; accepted 28 March 2002.

1. Garg, A. et al. J. Clin. Endocrinol. Metab. 84, 3390-3394 (1999).

2. Magre, J. et al. Nature Genet. 28, 365-370 (2001).

3. Eberhardt, C., Gray, P.W. \& Tjoelker, L.W. J. Biol. Chem. 272, 20299-20305 (1997)

4. Eberhardt, C., Gray, P.W. \& Tjoelker, L.W. Adv. Exper. Med. Biol. 469, 351-356 (1999).

5. Leung, D.W. Fron. in Biosci. 6, D1944-953 (2001)

6. West, J. et al. DNA Cell. Biol. 16, 691-701 (1997)

7. Lewin, T.M., Wang, P. \& Coleman, R.A. Biochemistry 38, 5764-5771 (1999)

8. Pages, C., Simon, M., Valet, P. \& Saulnier-Blache, J.S. Prostaglandins Other Lipid Mediat. 64, 1-10 (2001).

9. Hla, T., Lee, M.J., Ancellin, N., Paik, J.H. \& Kluk, M.J. Science 294, 1875-1878 (2001)

10. Fang, Y., Vilella-Bach, M., Bachmann, R., Flanigan, A. \& Chen, J. Science 294, 1942-1945 (2001).

11. Vigouroux, C. et al. J. Clin. Endocrinol. Metab. 82 3438-3444 (1997).

12. Seip, M. \& Trygstad, O. Acta Pædiatrica 413 (suppl.), 2-28 (1996).

13. Huseman, C., Johanson, A., Varma, M. \& Blizzard, R.M. J. Pediatr. 93, 221-226 (1978)

14. Garg, A., Fleckenstein, J.L., Peshock, R.M. \& Grundy, S.M. J. Clin Endocrinol Metab. 75, 358-361 (1992).

15. Oral, E.A. et al. N. Engl. J. Med. 346, 570-578 (2002). 